\title{
Production of Pectin from Orange Peel by using Trichosporon penicillatum
}

\author{
Ashok V. Gomashe, Minal A. Deolekar* and Vaidehi Chandorkar \\ Department of Microbiology, S.S.E.S.A s Science College, Congress Nagar, India \\ *Corresponding author
}

\begin{abstract}
A B S T R A C T
Keywords

Microbial extraction, orange peel, Trichosporon penicllatum, TLC technique

Article Info

Accepted: 18 April 2019 Available Online: 10 May 2019

The aim of this research is the production of pectin from orange peel by using Trichosporon penicillatum. Now-a-days, Pectin production has a market potential value on the basis of the growth prospectus of its users industries. Citrus peel of various origins contains $20-50 \%$ pectin on the dry matter basis. But, specifically orange peel contain the white spongy albedo in major content which contain $80-90 \%$ an appreciable amount of pectin without macerating the peel by using microbial method. Geotrichumklebanii ATCC 42397 Named Trichosporon penicillatum produces PPase-SE, anendopolyalacturonase with pectin releasing activity. It has the increasing energy demand on utilization of renewable agricultural and industrial waste. Different parameter was done for the maximum yield of pectin and it was about $6.50 \mathrm{gm} / 100 \mathrm{ml}$ at $40^{\circ} \mathrm{C}$ and incubation period of 24 hrs was the best. Pectin assay was done by using TLC technique which shows Rf value of about 0.74 . So orange peel waste was the best substrate for production of pectin gives highest yield which minimize the cost of production to improve the production level.
\end{abstract}

\section{Introduction}

Pectin substances are complex high molecular mass glycoside macro molecules found in higher plants. They are present in primary cell wall and are the major components of middle lamellae, a thin extracellular adhesive layer formed between the walls of adjacent young cells. In short, they are largely responsible for the structural integrity and cohesion of plant tissues.

Pectin is a complex polysaccharide consisting mainly of esterified D-galacturonic acid resides in an alpha-(1-4) chain. The acid groups along the chain are largely esterified with methoxy groups in the natural product. There can also be acetyl groups present on the free hydroxyl groups (Helene M, CanteriSchemin et al., 2005) (Fig. 1).

Pectin is found in fruit and vegetables and mainly prepared from 'waste' citrus peel. It makes up between about $2 \%$ and $35 \%$ of plant cell walls and is important for plant growth, regulation of ion and water exchange, development, and defense.

Pectin is a complex set of polysaccharide having properties such as gelation and emulsion stabilization which make it useful in manufacture of food, cosmetics and medicine. 
It is normal constituent of food and may therefore be safely ingested. It is also used as thickening agent for sauces, ketchups, flavoured syrups and texturing agent in fruit flavoured milk deserts(Girdhari Lal et al., 1998).There is increasing evidence that dietary pectin may have some health benefits beyond its role as a useful dietary fiber. Small pectin fragments have a positive effect as an anti-cancer agent as they bind to and inhibit the various actions of the pro-metastatic protein galectin-3 (E.G. Maxwell et al., 2012).consumption of pectin at least $6 \mathrm{~g} /$ day is necessary to have significant effect in cholesterol reduction. Amount less than $6 \mathrm{~g} /$ day of pectin are not effective (Ginter et al., 1979). citrus albedo of citrus fruits like apple pomace, lemon pulp, orange pulp are rich in pectic substance.( Fox, 1984 ) out of that, orange peel contain more thick albedo, which retain more pectin production by using Trichposporon penicillatum. (Geotrichumklebahnii ATCC 42397) yeast like fungus produces propectinase an endopolygalacturonase with pectin releasing activity. Muralikrishnan and Tharanathan (1994) extracted $1.47-5.37 \%$ pectin by soaking pulse husk in HCL and EDTA solution at $70^{\circ} \mathrm{C}$. (Miyazaki and Terada, 1974). In this process, we attempted pectin production by using $T$. penicillatum, orange peel as raw material and in so doing developed a new microbial method which can extract pectin from citrus peel without macerating the peel.

\section{Materials and Methods \\ Organism and inoculum preparation}

Fungal strain of Trichosporon penicillatum was procured from NCL PUNE (NATIONAL CHEMICAL LABORATORY), organisms maintained on potato dextrose agar at $40 \mathrm{c}$ and loopfull of spores was used as inoculum for further use.

\section{Processing of orange peel}

Peel waste were collected from local vendors. It was thoroughly washed then sliced and sliced into small pieces and sprayed on trays and then sieved pieces of waste fermented in tray and autoclaved at $15 \mathrm{lbs}$ for $20 \mathrm{mins}$ before use.

\section{Fermentation condition}

Fermentation media contains $\mathrm{NaH}_{2} \mathrm{PO}_{4} 5 \%$, $\mathrm{K}_{2} \mathrm{HPO}_{4} 12 \%$ and $\mathrm{MgSO}_{4} .7 \mathrm{H}_{2} \mathrm{O} 0.3 \%, \mathrm{CaCl}_{2}$ $0.5 \%$ and Ammonium Sulfate $1 \%$ and Sterile Pieces Of Orange Peel Were added into it and Flask were Incubatedat300C for $24 \mathrm{hr}$ in Incubator shaker at 120 RPM, medium were filtered and filtrate in which 1:3 ethanol were added as a solvent extraction and precipitated pectin was collected by centrifugation at 3000 $\mathrm{RPM}$ for $10 \mathrm{~min}$ at $28^{\circ} \mathrm{C}$ and extract was obtained and washed with ethanol and dried.

\section{Estimation of pectin}

TLC slide was prepared with silica gel and propanol: ammonia: water (10:1:1) were taken in beaker as a solvent system. Extract was spotted on TLC plate and allowed to stand for $20 \mathrm{~min}$ and the slide was inserted into the solvent containing beaker and iodine crystals were sprayed on beaker and allow it stand for $10 \mathrm{~min}$ and calculate the Rf value. During the pectin assay, $\mathrm{Rf}$ value was calculated that is

$\mathrm{Rf}=$

Distance spot travels

Distance solvent travels

Where $\mathrm{Rf}$ is Retardation factor value which was found to be 0.74 and compare the standard $\mathrm{Rf}$ value of pectin is 0.81 by TLC technique. 
The Rf value was found to be 0.74 which was compared with standard Rf value of pectin.

\section{Results and Discussion}

Effect of different parameters on pectin production.

Strain grew well in the extract of citrus peel as a nutrient source. In pectin production, optimum temperature and incubation period gives maximum yield of pectin production in broth as shown in Table 1 and 2 .

Extraction was carried at different time below graph represents maximum yield of pectin at $24 \mathrm{hr}$. Temperature has been observed to be one of the major process variables affecting the production of pectin, although microorganism grew well between 25 and $37^{\circ} \mathrm{C}$. Attempt of $400 \mathrm{c}$ was chosen as the best temperature for the extraction.

The effect of time was examined, during time variable pectin began to appear after 5 hour and increased with time after 20 to $25 \mathrm{hr}$, the amount of pectin extracted reach. This was analyzed at every $24 \mathrm{hr}$ time intervals and maximum yield was found to be at $24 \mathrm{hrs}$. after $24 \mathrm{hr}$ Graph 2 represents there was gradual increase in the yield upto $96 \mathrm{hrs}$, this might be on the basis of consumption of nutrients. Watermelon rind pectin extraction was investigated using acid and enzymatic extraction, acid extraction was conducted using nitric acid and precipitated with isopropanol. Extraction conditions of 45minutes, $\mathrm{pH} 1.65$ and $0.258 \mathrm{~g} / \mathrm{ml}$ solid to liquid ratio resulted in pectin yield of $20.02 \%$ (Mary Campbell Oklahoma State University, December 2006).

Rao and Miani (1999) reported $18.4 \%$ yield in orange mandarin peels. Lotha et al., reported $6-8 \%$ pectin from kinnow. Pectin in diets of human and lab animals has been shown to increase the excretion of lipids, cholesterol, bile acids and reduce serum cholesterol levels. Pectin operates by binding with bile acids thereby decreasing cholesterol and fat absorption.

There is also evidence that regular use of pectin may lessen the severity of diabetes (siddappa and Tandon, 1998).

Table.1 Effect of Temperature on pectin production by T. penicillatum

\begin{tabular}{|l|l|}
\hline Temperature & $\begin{array}{l}\text { Pectin Yield in } \\
\text { gm/100ML }\end{array}$ \\
\hline $\mathbf{3 0}$ & 4.30 \\
\hline $\mathbf{3 7}$ & 4.00 \\
\hline $\mathbf{4 0}$ & 6.50 \\
\hline $\mathbf{4 5}$ & 3.70 \\
\hline
\end{tabular}

Table.2 Effect of Incubation period on pectin production by T. penicillatum

\begin{tabular}{|l|l|}
\hline $\begin{array}{l}\text { Incubation } \\
\text { period (time) }\end{array}$ & $\begin{array}{l}\text { Pectin Yield in } \\
\text { gm/100ML }\end{array}$ \\
\hline $\mathbf{2 4 h r}$ & 5.30 \\
\hline $\mathbf{4 8 h r}$ & 2.40 \\
\hline $\mathbf{7 2 h r}$ & 3.30 \\
\hline $\mathbf{9 6 h r}$ & 4.40 \\
\hline
\end{tabular}


Fig.1 Structure of pectin

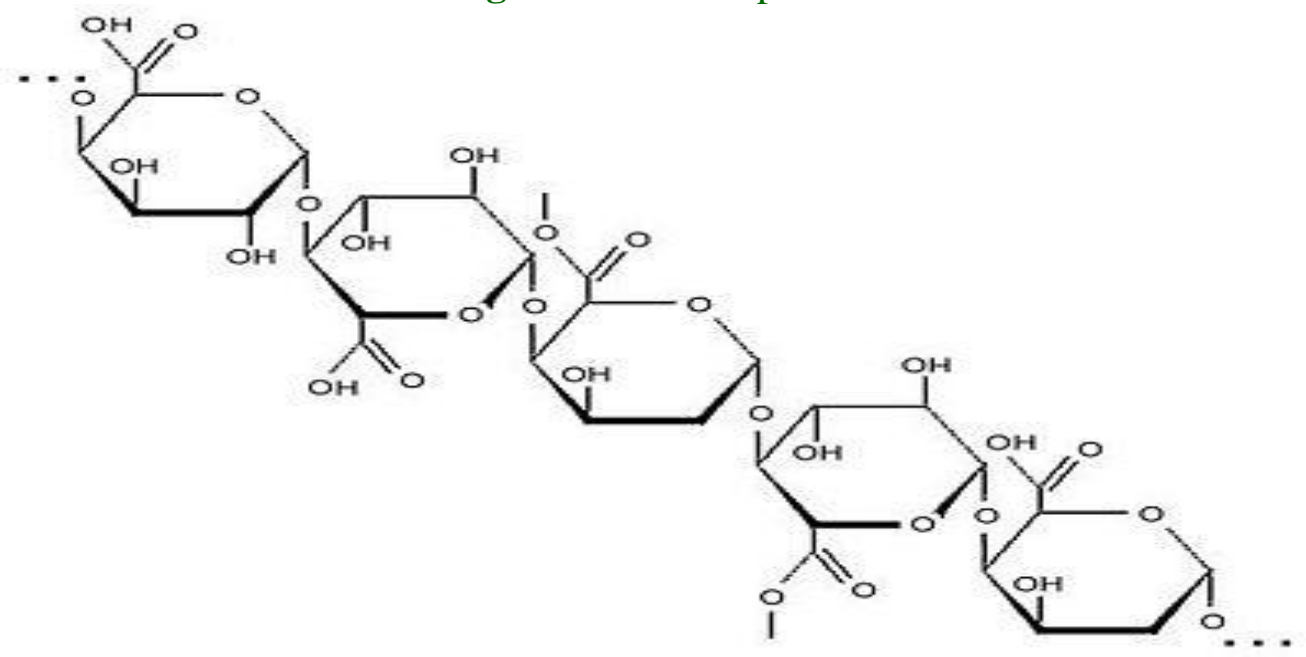

Graph.1 Yield of pectin production at effect of different temperature

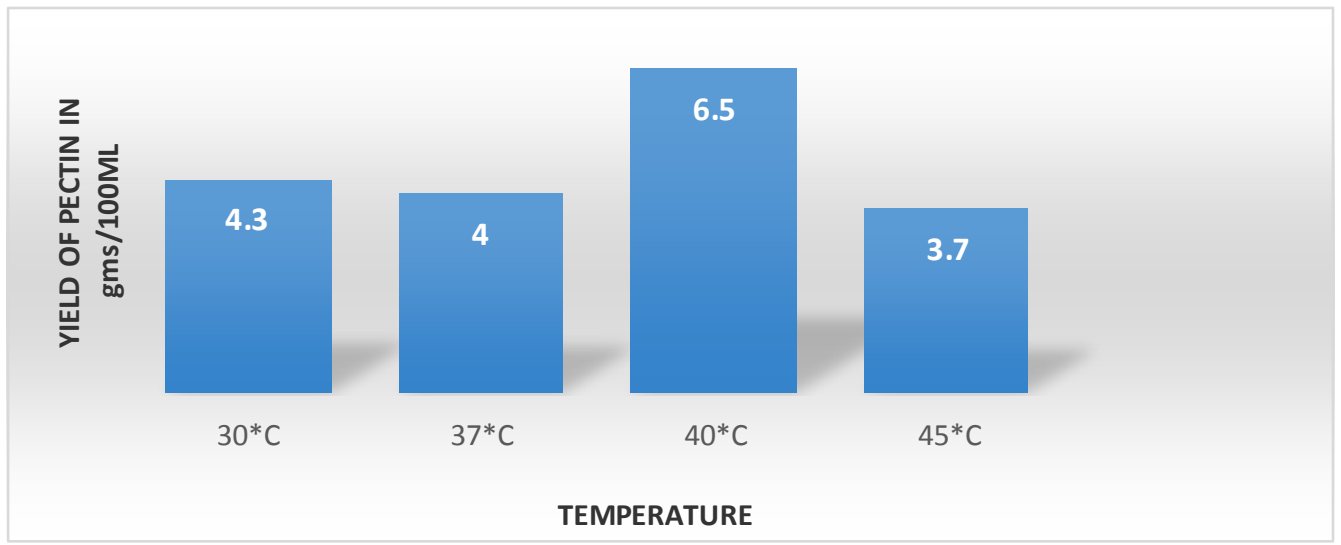

Graph.2 Yield of pectin production at effect of different incubation period

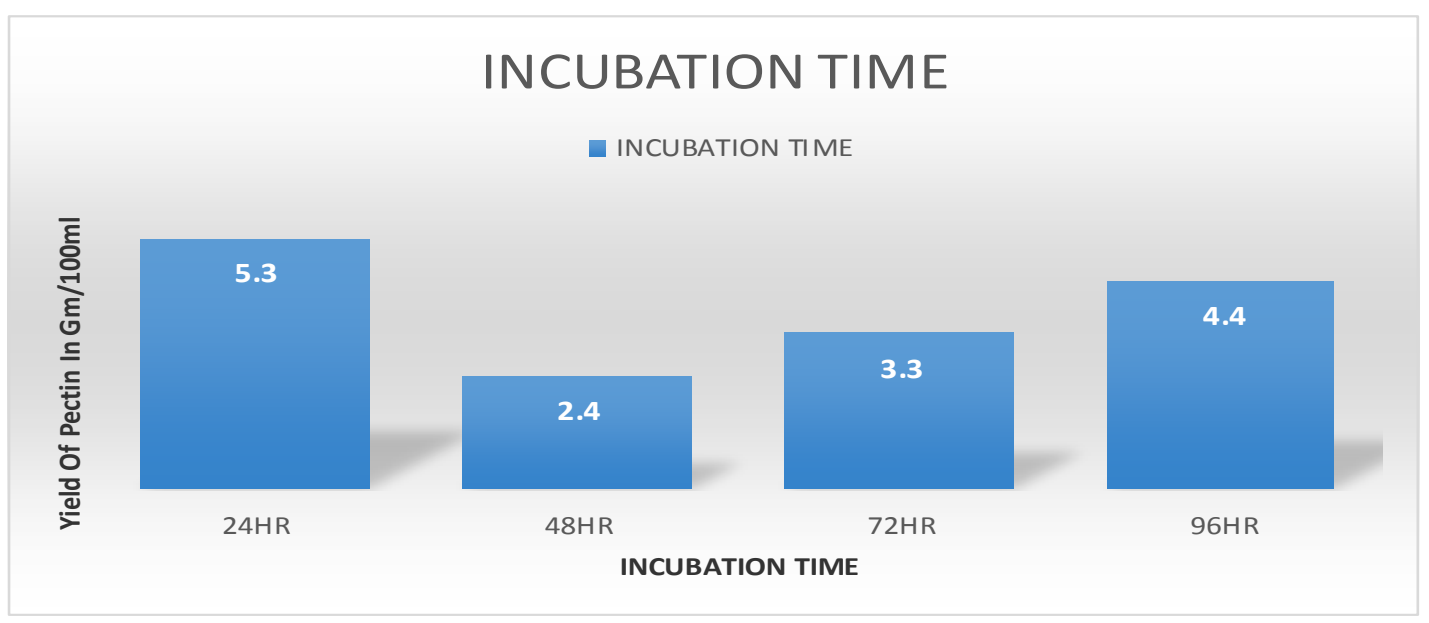


Extraction was carried out at different temperature and above graph represents maximum yield of production at $400 \mathrm{c}$ as shown in graph 1.

In conclusion, the microbial extraction method was efficient in the yield of pectin whereas orange peel waste was the best substrate for production of pectin. For the highest yield of pectin suitable time and temperature was found to be 400c for $24 \mathrm{hrs}$. Use of waste may minimize the cost of production and optimization may help to marginally improve the production level.

\section{References}

Chen G, Zhang H And Zhang Q 1999. Extraction of pectin from potato wastes by salt sedimentation. Shipin Kexue.

Elian An, Fodams and Attia L. 1984. Production pectin and pigments from orange peel by using microbial enzymes. Egypt J. Food Science.

Ginter,EEt al (1979) Natural hypocholesterolemic agent: pectin plus ascorbic acid. International Journal Of Viticulture And Natural Resource
Girdhari Lal; Siddapa, G.S and Tandon G.L. 1998. Manufacture of pectin. preservation of fruits and vegetables, Indian Council Of Agricultural Research, New Delhi.

Nand, K. 1998 Recent advances in the treatment of liquid and solid wastes of food processing industries of biogas production and pollution.

PilnikW, Voragen A.G.N. 19992. Gelling agents (pectins) from plants for the food industry, Advanced In Plant Cell Biochemistry And Biotechnology.

Sakai T. M Okushima 1980 Microbial production of pectin from citrus peel. Applied and Environmental Microbiology.

Scheming M.H.C, Fertonani, HCR, Waszcynskyin Wosiacki G. 2005. Extraction of pectin from apple pomace, Braz Branch Of Biotechnology.

Sriamornsak, P(2001-2002) Pectin. The Role In Health Journal Of Silpakorn University.

Thakur B.R et al., (1997) Chemistry And Uses Of Pectin- A Review ,Critical Reviews In Food Science And Nutrition.

\section{How to cite this article:}

Ashok V. Gomashe, Minal A. Deolekar and Vaidehi Chandorkar. 2019. Production of Pectin from Orange Peel by using Trichosporon penicillatum. Int.J.Curr.Microbiol.App.Sci. 8(05): 2278-2282. doi: https://doi.org/10.20546/ijcmas.2019.805.268 